\title{
MARQUES, Janote Pires. Festas de negros em Fortaleza. Territórios, sociabilidades e reelaborações (1871-1900). Fortaleza: Expressão Gráfica, 2009. ISBN 978-85-7563-229-1. 264 p.
}

Qual a contribuição dada pelo negro à formação social cearense? Para responder à pergunta, Janote Pires Marques rastreia, exatamente, nas fontes que negam tal contribuição,

a significativa presença negra na constituição do substrato cultural da "Cidade das Luzes". Universos culturais, sociabilidades e territórios negros são mapeados. As diversas manifestações culturais se apresentam como depositárias de uma memória, de um legado que sinaliza a renitente permanência e capacidade criativa das comunidades negras.

Ao descrevê-las detalhadamente, Marques convida seus futuros leitores a percebê-las como formas de cultura e sociabilidade e a mudar o seu olhar sobre a "Cidade das Luzes". Estabelece como recorte temporal o período de 1871 a 1900, "um período em que as manifestações festivas de negros- coroações de reis na irmandade do Rosário, autos de rei do congo, sambas, maracatus, constituíam importantes territórios de reelaborações culturais e de diversas práticas de sociabilidades, afetadas de forma intensa pelas mudanças sociais e políticas ocorridas em Fortaleza e no Brasil nas últimas décadas do XIX”. (p.29-30).

Essas e outras veredas encontramos em Festas de Negros em Fortaleza. Territórios, sociabilidades e reelaboraçôes(1871-1900), de Janote Pires Marques. Além do belo material iconográfico e de uma cuidadosa edição, o livro, na observação precisa de Franck Ribard, demonstra com clareza e base documental que, "apesar da violência simbólica representada pelo movimento histórico de 'naturalização' da ideia da ausência ou do caráter insignificante da participação e da contribuição negra na formação social cearense, a perenidade da dinâmica cultural e da consciência identitária dos negros, mulatos e pardos, atesta de outras lógicas e vivências"(RIBARD apud MARQUES, p.17).

Não por nada, Festas de Negros em Fortaleza foi agraciado com Premio V Edital de Incentivo às Artes da Secretaria de Cultura do Estado do Ceará.

Organizado em três longos capítulos, intitulados Negros no Ceará: discursos, experiências e festas; Irmandade, congos e sambas: controle, transgressão e sociabilidades e "Para os pretos plebeus, maracatu e samba": reelaboração cultural e (re)apresentação do sagrado", apresenta uma investigação audaciosa e cativante sobre a presença dos negros na constituição do substrato cultural do Ceará. 
$246 \mid$ Ênio José da Costa Brito

\section{Imagens do Negro cearense}

A província do Ceará até hoje se vangloria, e com razão, de por primeiro ter libertado seus escravos, em 24 de maio de 1883 . A década de 1870 e 1880 viu crescer o movimento abolicionista no Ceará, com a criação de várias Sociedades Libertadoras; a primeira teria sido a de Baturité (25/05/1870), seguida da Sociedade Manumissora Sobralense(25/06/1870).

E em 1879 surgiu a Sociedade "Perseverança e Porvir", em Fortaleza. As duas sociedades mais importantes foram a Sociedade Cearense Libertadora(8/12/1880) e o Centro Abolicionista(19/12/1882), ambas em Fortaleza. As mulheres também constituíram a Sociedade das Cearenses Libertadoras (6/01/1883).

No entanto, “apoiado em argumentos de 'patriotismo' e 'progresso', o movimento abolicionista convergiu para a elevação de uma causa-a abolição-, em que o negro escravo não era o fim, mas o meio pelo qual se glorificaria a luta pela liberdade, personificada na figura dos libertadores”. (p.42)

A ausência da voz e da letra dos negros nas campanhas da abolição, nas comemorações e nos discursos, não só deixa transparecer preconceitos, como contribui para o não reconhecimento do negro como sujeito. Para a elite cearense, além de o negro ser um sujeito inerte, era dado a práticas culturais atrasadas, geradoras de desordem e, por isso mesmo, condenáveis. Mas, apesar dos preconceitos, as festas continuavam a acontecer com frequência pela cidade.

São muitos os indicativos de sociabilidade dos negros, em Fortaleza, que não só negam a passividade, como deixam entrever as suas capacidades de negociação, resistência e criatividade. Entre esses indícios pode-se enumerar: as práticas transgressoras- enganar, agredir, transpor limites, dissimular-, a preocupação das autoridades com o controle dos ofícios, dos divertimentos e das festas, presente nos inúmeros códigos de postura (1835, 1865, 1870, e 1879), e os anúncios de fuga de escravizados. Indícios reveladores de indivíduos com saberes e quereres, com uma compreensão própria da liberdade, com sagacidade para construir relaçôes nas brechas do sistema. A imagem do escravizado que emerge desses indícios está longe de ser a imagem que povoa o discurso dos abolicionistas.

“Enquanto os 'libertadores' espetacularizavam as concessões de carta de alforria e promoviam cerimônias abolicionistas e cívicas, os cativos trabalhavam e conseguiam acumular recursos para comprar sua liberdade, mas também para fazer festas que constituíam espaços onde os negros (cativos e livres) se reuniam, praticavam uma cultura afro-brasileira, estabeleciam comunicações com os demais atores sociais, ocupavam territórios na cidade e, principalmente, mantinham-se como sujeitos capazes de fazer história”. (p.73) 


\section{Festas e irmandade em Fortaleza}

Festas, em Fortaleza, como as coroações de reis negros na Irmandade do Rosário, os autos de rei congo e os sambas, se constituíam em importantes espaços de manifestação cultural, além de refletirem dinâmicas identitárias. "Essas diferentes dimensões ilustram como as festas de negros eram territórios onde os grupos sociais criavam representações e redes relacionais por intermédio de suas práticas culturais, produzindo significados por meio de símbolos pertencentes a suas culturas, ou se apropriando de outros em um processo dinâmico de ressignificação". (p.89)

No entanto, as posturas municipais reiteradamente confirmavam a ausência do negro como produtor de cultura. As festas de negro, mesmo acontecendo num momento em que a cidade passava por transformações sociais e físicas, transpassaram a dinâmica socioespacial de Fortaleza e perduraram.

Em Fortaleza, o maior espaço de organização social dos negros na segunda metade do século XIX foi a Irmandade de Nossa Senhora do Rosário dos Homens Pretos. A criação de uma Irmandade passava por um longo e intrincado processo de negociação. Entre suas atividades, destacava-se a festa da coroação de reis negros. "A festa homenageava Nossa Senhora, mas, ao mesmo tempo, celebrava uma manifestação ancestral africana materializada na eleição e coroação de reis negros". (p.96)

A popularidade de Nossa Senhora do Rosário entre os negros era indiscutível - sua figura ligada a vitórias militares, a libertação e certa familiaridade do rosário com o rosário de Ifá (Orixá), estão na base desta popularidade. A devoção a Nossa Senhora do Rosário teve seu esplendor no século XVIII e, durante todo o século XIX, a Irmandade de Nossa Senhora do Rosário foi uma presença ativa na cidade. Os libertos e cativos, ao se tornarem "filhos" de Nossa Senhora do Rosário, assumiam uma identidade reconhecida tanto pela Igreja como pelo Estado.

Os compromissos de 1840 e de 1871 dão a conhecer um pouco da organização e da vida da Irmandade. O segundo, redigido pelos irmãos em pleno processo de romanização, deixa transparecer exigências da Igreja e uma forte solidariedade entre os irmãos. Na Irmandade, a cosmovisão católica e a africana se faziam presentes, muitos elementos simbólicos católicos foram apropriados e certamente relidos, como o sepultamento, a cruz e o culto aos mortos.

Um evento revelador da força e da autonomia da Irmandade era a festa de Nossa Senhora do Rosário, que o compromisso recomendava que fosse realizada com pompa e solenidade. Na festa, elegia-se o Rei e a Rainha. O Rei exercia sua soberania num território cultural amplo. Muitos organizadores de congos acabaram sendo eleitos reis, por sua capacidade de agregar a comunidade negra e por 
248 Ênio José da Costa Brito

seus contatos políticos. "Portanto, a presença dos reis congos nas irmandades do Rosário dos Homens Pretos indica que essas confrarias não eram simples espaços de acomodação onde os negros aceitavam passivamente as influências culturais dos senhores. Cultuava-se Nossa Senhora, mas, ao mesmo tempo, abria-se a porta da igreja para personagens que entre os negros da cidade simbolizam uma manifestação ancestral africana”(p.115).

\section{Congos e Sambas}

Uma festa importante realizada na cidade de Fortaleza durante o ciclo natalino era a dos congos, uma encenação de eventos ocorridos na África (séculos XVI e XVII).A associação dos "reis congos" com os "reis magos" facilitou a aceitação da festa pela sociedade da cidade.

Os congos são reelaborações de uma cultura de raízes africanas. Mantiveram-se sempre atuais graças às suas adaptações e à incorporação de gêneros musicais diferentes, sem perder suas raízes africanas. Os congos entravam em constante diálogo com outras práticas festivas, como os bumba-meu-boi, sambas e maracatus e fandangos.

"Parece evidente que os congos cantavam uma África distante, muitas vezes adulterando nomes e fatos, não sendo isso erro de interpretação histórica, mas um indicativo de que era a capacidade dos negros de recriarem um passado que fazia essa cultura de raízes africanas existir do outro lado do Atlântico". (p.135)

Outra importante manifestação festiva era o samba, presente tanto na zona urbana quanto na rural. O termo samba reveste-se de complexidade, como se pode constatar lendo as explicações dadas por Câmara Cascudo, Nei Lopes e Edison Carneiro. Entretanto, é possível "identificar nos sambas aspectos como a influência de uma cultura de origem africana (banto) no Ceará; o samba como espaço de resistência do negro; reuniões em samba como diversão e transgressão; o samba como laboratório de (re)criação cultural em que participam negros (escravos, libertos, nascidos livres) e brancos oriundos de vários extratos da sociedade cearense". (p.150) Mas, o samba não era apenas um espaço onde costumes de matriz africana eram recriados, mas, também, de apropriação de elementos europeus(a viola).

Reprimido pela polícia, desprezado pela elite e pela Igreja, o samba resistiu, mostrando o papel ativo dos negros, reelaborando suas raízes e transgredindo normas para realizar seus desejos.

\section{"Criatividade reelaboradora"}

As festas de negros em Fortaleza compartilhavam tempos e espaços comuns, revelando "outra cidade". As inúmeras tentativas de cerceamento não só fracassaram 
como, muitas vezes, estimularam a maior inter-relação entre elas, a circularidade entre seus sujeitos e até seu multiplicar-se. $\mathrm{O}$ processo de ressignificação, presente em todas as festas negras, foi mais intenso nos maracatus. Para o autor, o maracatu cearense deita raízes na presença de uma "consistência cultural"(Gilberto Velho) cearense e está longe se ser uma cópia do maracatu de Recife. Sua reconstituição, na década de 1930, parte de matérias primas acumuladas ao longo do tempo. (pp.179,194)

"As festas de negros e sua inerente força criativa foram poderosos instrumentos pelos quais se revelou a capacidade de os negros constantemente praticarem uma cultura não dependente de 'incentivos' das autoridades, e produzirem uma identidade cultural que transpôs preconceitos, cerceamentos, perseguiçôes da polícia; enfim, todas as dificuldades presentes na dinâmica socioespacial e histórica da cidade de Fortaleza". (p.181) Essa criatividade reelaboradora, imanente às festas de negros, mantinha viva uma dinâmica de criação geradora de uma identidade cultural e étnica.

O deslocamento da corte da Irmandade do Rosário e dos congos para o maracatu e sua permanência é um dos exemplos da resistência do negro e de suas práticas culturais em Fortaleza. Outra presença significativa é a da calunga, nos maracatus e em outras manifestaçôes. Não se trata apenas de uma boneca, mas de um objeto simbólico, com uma função mágico-religiosa ou sagrada. $\mathrm{O}$ uso de máscaras e pinturas traz um forte componente sagrado, que também se faz presente nos Cucumbis, um auto de inspiração angolana, relacionado com a vida e a morte.

\section{Considerações}

Percebe-se, hoje, a importância e o desafio de se investigar o universo de vida de africanos escravizados, que não legaram ou, então, nos deixaram pouquíssimas memórias escritas.Importância, posto que permite romper o enquadramento dos africanos ora como força de trabalho, ora como seres exóticos. Dinâmica até pouco tempo atrás presente na historiografia. Desafio, uma vez que se trata de buscar indícios em documentos escritos por aqueles que detinham o poder e os códigos da escrita.Para os historiadores João Reis, Flávio Gomes e Marcus Carvalho, "a história dos africanos no Brasil do tempo da escravidão, em grande parte, é escrita a partir de documentos policiais"1.

Robert Slenes, em "Lares negros, olhares brancos...", mostrou como os escritos dos viajantes -e, poderíamos acrescentar, dos memorialistas - são textos a

\footnotetext{
${ }^{1}$ REIS, João José; GOMES, Flávio dos Santos; CARVALHO, Marcus P. J. de. O Alufá Rufino. Tráfico, escravidão e liberdade no Atlântico Negro (c.1822-c.1853). São Paulo: Companhia das Letras,2010, p.9)
} 
$250 \mid$ Ênio José da Costa Brito

serem explorados com discernimento, pois são plenos de sentido, mas portadores de preconceitos culturais e julgamentos morais. Seu conselho é dar atenção, dar valor aos detalhes registrados, passíveis de sistematização pelo historiador ${ }^{2}$.

Janote Pires Marques, em Festas de Negros em Fortaleza, acolhe o desafio de mergulhar na leitura dos memorialistas e de outras fontes e no cotidiano de escravizados e livres para extrair deles as contribuiçôes culturais. Pesquisa cuidadosa, que resgata práticas festivas, tradições genuínas e fundamentais do patrimônio cearense.

Práticas festivas capazes de expressar uma cultura negra que marcava a "memória” de seus tantos frequentadores, como eles construíam espaços identitários, de sociabilidades e resistência numa cidade que se modernizava a passos rápidos.

Ao rastrear indícios dispersos, difusos nas brechas e frestas da vida cotidiana dos escravizados em Fortaleza, desvela para o leitor como os negros- cativos ou livres-, potencializavam seus divertimentos de tal modo que, sem deixarem de ser momentos de diversão, de extravasar as tensões acumuladas no cotidiano, se constituíram em espaços de resistência, identidade, cultura e sociabilidade.

Ao acompanhar as inúmeras ressignificações presentes nas práticas culturais africanas em Fortaleza, o autor explicita implicitamente a contribuição das mesmas na formação da sociedade e cultura brasileiras. Contribuição que ainda não recebeu a devida atenção dos meios acadêmicos.

Senti falta de um diálogo com Michel Foucault, sobre a presença camuflada de um feroz poder disciplinador a regrar a vida dos munícipes brancos, pardos e negros da cidade de Fortaleza, em inúmeras passagens o texto abre espaço para esta reflexão.

Uma palavra sobre a apresentação gráfica do livro: ela revela competência editorial e um profundo carinho para com os futuros leitores. $\mathrm{O}$ texto muito leve e fluente cria um processo de interação entre o autor e o leitor, facilitando a leitura. Ler Festas de Negros em Fortaleza proporciona prazer visual e intelectual. É ler para experimentar.

\section{Ênio José da Costa Brito}

Recebido: 08/04/2011

Aprovado: 31/05/2011

\footnotetext{
${ }^{2}$ SLENES, Robert W. Lares negros, olhares brancos. História da família escrava no século XIX, in: REVISTA BRASILEIRA DE HISTÓRIA, São Paulo: ANPUH ; Marco Zero, v.8, n.16, 1988.
} 